\title{
Input-Specific Long-Term Depression in the Lateral Amygdala Evoked by Theta Frequency Stimulation
}

\author{
Thomas Heinbockel and Hans-Christian Pape \\ Otto-von-Guericke-Universität, Institut für Physiologie, D-39120 Magdeburg, Germany
}

Although conditioned fear has been shown to involve mechanisms of synaptic plasticity in the amygdala, the association with afferent input systems is not yet clear. Here we report on homosynaptic long-term depression (LTD) of excitatory responses after stimulation of putative thalamic input fibers, but not of cortical inputs, to the rat lateral amygdala in vitro. LTD is induced by theta frequency stimulation and involves postsynaptic calcium-dependent mechanisms and group II metabotropic glutamate receptors. These input-specific changes in synaptic strength represent potential cellular sources, which regulate the balance between sensory thalamic and cortical input signals to the amygdala. This regulation would function to reduce the influence of relatively undiscriminated stimulus information carried by thalamic afferents in favor of discriminated sensory information mediated by the cortex during fear responses.

Key words: amygdala; fear conditioning; lateral amygdala; long-term depression; synaptic plasticity; theta
The amygdala is a key component of the neuronal circuitry involved in Pavlovian fear conditioning (LeDoux, 1995; Maren and Fanselow, 1996; Fanselow and LeDoux, 1999; Maren, 1999). Afferent sensory input, mediated via thalamic and cortical fibers, reaches the amygdala through its lateral nucleus (LA) (Pitkänen et al., 1998). The two major input pathways are functionally distinct but converge onto single projection neurons in the LA (LeDoux, 1995; Mahanty and Sah, 1999). In the case of auditory input, thalamic afferents rapidly carry relatively undiscriminated and impoverished stimulus information, whereas cortical afferents convey more discriminated, contextual information (LeDoux, 1995; Li et al., 1996). Different forms of activity-dependent synaptic plasticity have been reported to occur in the amygdala, one of which, long-term potentiation (LTP), has been suggested to be an important cellular mechanism for conditioned fear (Maren and Fanselow, 1995; McKernan and Shinnick-Gallagher, 1997; Rogan et al., 1997; Huang and Kandel, 1998; Maren 1999). Other forms include bidirectional synaptic plasticity (depression and potentiation) that is sensitive to the type and sequence of the stimulation paradigm used (Li et al., 1998), and LTP in GABAergic interneurons in the basolateral amygdaloid complex (Mahanty and Sah, 1998). In a very recent paper, long term depression (LTD) has been reported to occur in an intra-amygdaloid pathway (Wang and Gean, 1999). However, it is not yet clear how the different input systems relate to the depression of synaptic transmission in the amygdala and to conditioned fear. Here, we show that lasting depression of synaptic excitatory responses occurs at one of the two major sensory input systems: the thalamic one, whereas the cortical input system is relatively unaffected.

Parts of this study have been reported previously in abstract form (Heinbockel and Pape, 1999a,b).

\footnotetext{
Received Dec. 13, 1999; revised Jan. 24, 2000; accepted Jan. 27, 2000.

This work was supported by Deutsche Forschungsgemeinschaft Grant SFB 426 TP B3. We thank A. Reupsch and R. Ziegler for expert general laboratory assistance and R. Driesang for help with the analysis program.

Correspondence should be addressed to Hans-Christian Pape, Institut für Physiologie, Leipziger Strasse 44, D-39120 Magdeburg, Germany. E-mail: HansChristian.Pape@medizin.uni-magdeburg.de.

Copyright $(\subset 2000$ Society for Neuroscience $0270-6474 / 00 / 200001-\bullet \$ 15.00 / 0$
}

\section{MATERIALS AND METHODS}

Frontal amygdaloid slices were prepared from deeply anesthetized Long-Evans rats (halothane anesthesia; Zeneca, Plankstadt, Germany) of either sex (postnatal days 25-30) (Heinbockel and Pape, 1999c). Slices were kept in an interface-type chamber during continuous superfusion with a solution containing (in $\mathrm{mm}$ ): $\mathrm{NaCl} 126, \mathrm{KCl} 2.5, \mathrm{MgSO}_{4} 2$, $\mathrm{NaHCO}_{3} 26, \mathrm{NaH}_{2} \mathrm{PO}_{4} 1.25$, dextrose 10 , and $\mathrm{CaCl}_{2} 2$, buffered to $\mathrm{pH}$ 7.4 with $95 \% \mathrm{O}_{2}-5 \% \mathrm{CO}_{2}$.

Intracellular recordings from a total of 146 neurons were performed with glass microelectrodes (TW-100F; World Precision Instruments, Sarasota, FL) and controlled with a bridge amplifier (Axoclamp-2B; Axon Instruments, Foster City, CA). Electrode DC resistances ranged $60-80 \mathrm{M} \Omega$ (filled with $4 \mathrm{M} \mathrm{K}$-acetate) and 100-150 $\mathrm{M} \Omega$ (with inclusion of BAPTA, $200 \mathrm{~mm}$ ). All membrane potential measurements were corrected for electrode offsets (typically $<5 \mathrm{mV}$ ).

Projection neurons were identified based on morphological (after Biocytin injection and histological processing) and electrophysiological criteria, namely spine-rich dendrites and the generation of slow oscillations of the membrane potential (Washburn and Moises, 1992b; Paré et al., 1995; Pape and Driesang, 1998; Pape et al., 1998). Neurons were considered for analysis that had a stable resting membrane potential negative to $-60 \mathrm{mV}$, resting input resistances $>45 \mathrm{M} \Omega$ (as determined from responses to hyperpolarizing current pulses, -0.1 to $-0.3 \mathrm{nA}$ ), and overshooting action potentials.

Synaptic responses were evoked with two bipolar tungsten electrodes placed in the external and close to the internal capsule for stimulation of putative cortical and thalamic afferents, respectively (Mahanty and Sah, 1999; Weisskopf and LeDoux, 1999). Stimulus intensity was adjusted to produce a synaptic response $30-50 \%$ of maximum amplitude without triggering action potentials. All neurons were held at resting membrane potential. Single pulses $(100 \mu \mathrm{sec})$ were applied as control stimuli at 0.05

This article is published in The Journal of Neuroscience, Rapid Communications Section, which publishes brief, peerreviewed papers online, not in print. Rapid Communications are posted online approximately one month earlier than they would appear if printed. They are listed in the Table of Contents of the next open issue of JNeurosci. Cite this article as: JNeurosci, 2000, 20:RC68 (1-5). The publication date is the date of posting online at www.jneurosci.org.

http://www.jneurosci.org/cgi/content/full/4052 
$\mathrm{Hz}$ alternating for each pathway. Typically, electrical stimulation evoked a triphasic sequence of a fast EPSP, followed by a fast and a slow IPSP (Rainnie et al., 1991a,b; Washburn and Moises, 1992a; Danober and Pape, 1998). EPSPs could not be pharmacologically isolated from the IPSPs because of the development of epileptiform burst discharges in disinhibited slices (Gean and Chang, 1991; Rainnie et al., 1991a; Danober and Pape, 1998). Theta frequency stimulation (stimuli of the predetermined strength at $8 \mathrm{~Hz}$ for $150 \mathrm{sec}$ ) was applied only once at the thalamic and the cortical pathways in a given slice.

Pharmacologically active substances were applied by local superfusion (Danober and Pape, 1998) through pipettes (tip diameter, 10-20 $\mu \mathrm{m}$ ) by constant low pressure (Picospritzer II; General Valve, Fairfield, NJ). The drugs used were BAPTA (Sigma, St. Louis, MO), Calyculin A (Calbiochem, La Jolla, CA), (2S)- $\alpha$-ethylglutamic acid (EGLU), $(2 S, 3 S, 4 S)$-2(carboxycyclopropyl)glycine (L-CCG), and ( $2 S, 3 S, 4 S$ )-2-methyl-(carboxycyclopropyl)glycine (MCCG) (Tocris, Biotrend, Köln, Germany). Data are presented as means \pm SEM. Values for individual cells were averaged amplitudes of six subsequent EPSPs. EPSP amplitudes were normalized with respect to stable responses $10 \mathrm{~min}$ before theta frequency stimulation. Data at post-theta stimulation were compared with those of pre-theta stimulation, and the Student's $t$ test was used for statistical analysis (Dixon and Massey, 1969).

\section{RESULTS}

Intracellular recording techniques were used in an in vitro slice preparation (Long-Evans rats) to study the synaptic responses of projection neurons in the LA to electrical stimulation of either putative thalamic or cortical input fibers. Single electrical stimulation of either input typically evoked a triphasic sequence of a fast glutamate receptor-mediated EPSP, followed by a fast and a slow component of IPSPs mediated via $\mathrm{GABA}_{\mathrm{A}}$ and $\mathrm{GABA}_{\mathrm{B}}$ receptors, respectively (Rainnie et al., 1991a,b; Washburn and Moises, 1992a; Danober and Pape, 1998).

\section{Input specificity of LTD}

In a population of projection neurons in the LA (21\% of the tested neurons; $n=52$ ), theta frequency stimulation (single stimuli at $8 \mathrm{~Hz}$ for $150 \mathrm{sec}$ ) of putative thalamic input fibers resulted in an LTD (>30 min) of EPSP amplitude evoked with single thalamic control stimuli (Fig. $1 A, B$ ). The LTD typically developed during the stimulation period and in some cases increased further thereafter. The LTD was observed for periods of $>100$ min (data not shown). The same stimulation had no effect on EPSPs evoked with single control stimuli delivered to cortical afferents. Subsequent theta frequency stimulation of these putative cortical input fibers did not result in a lasting change of EPSP amplitude of either input pathway (Fig. $1 A$ ). The homosynaptic depression of EPSPs occurred irrespective of the order of theta frequency stimulation of the two pathways (Fig. 1C).

In addition, a second theta frequency stimulation of putative thalamic inputs $30 \mathrm{~min}$ after the first stimulation did not further increase the depression (data not shown), whereas IPSPs were briefly potentiated (see below). Other projection neurons in the LA showed either no changes in synaptic strength in response to theta frequency stimulation $(23 \%)$ or synaptic depression that either lasted $<30 \mathrm{~min}$ or was $<20 \%$ in amplitude and, therefore, were not included in the analysis.

No long-term changes of inhibitory responses were observed. Typically, short increases (duration $<5 \mathrm{~min}$ ) in amplitude of both $\mathrm{GABA}_{\mathrm{A}^{-}}$and $\mathrm{GABA}_{\mathrm{B}}$-mediated components occurred in projection neurons (data not shown). This short-term change in inhibitory synaptic responsiveness was evoked by stimulation of either thalamic or cortical input fibers and was restricted to the stimulated afferent pathway, presumably indicating presynaptic effects on inhibitory interneurons.

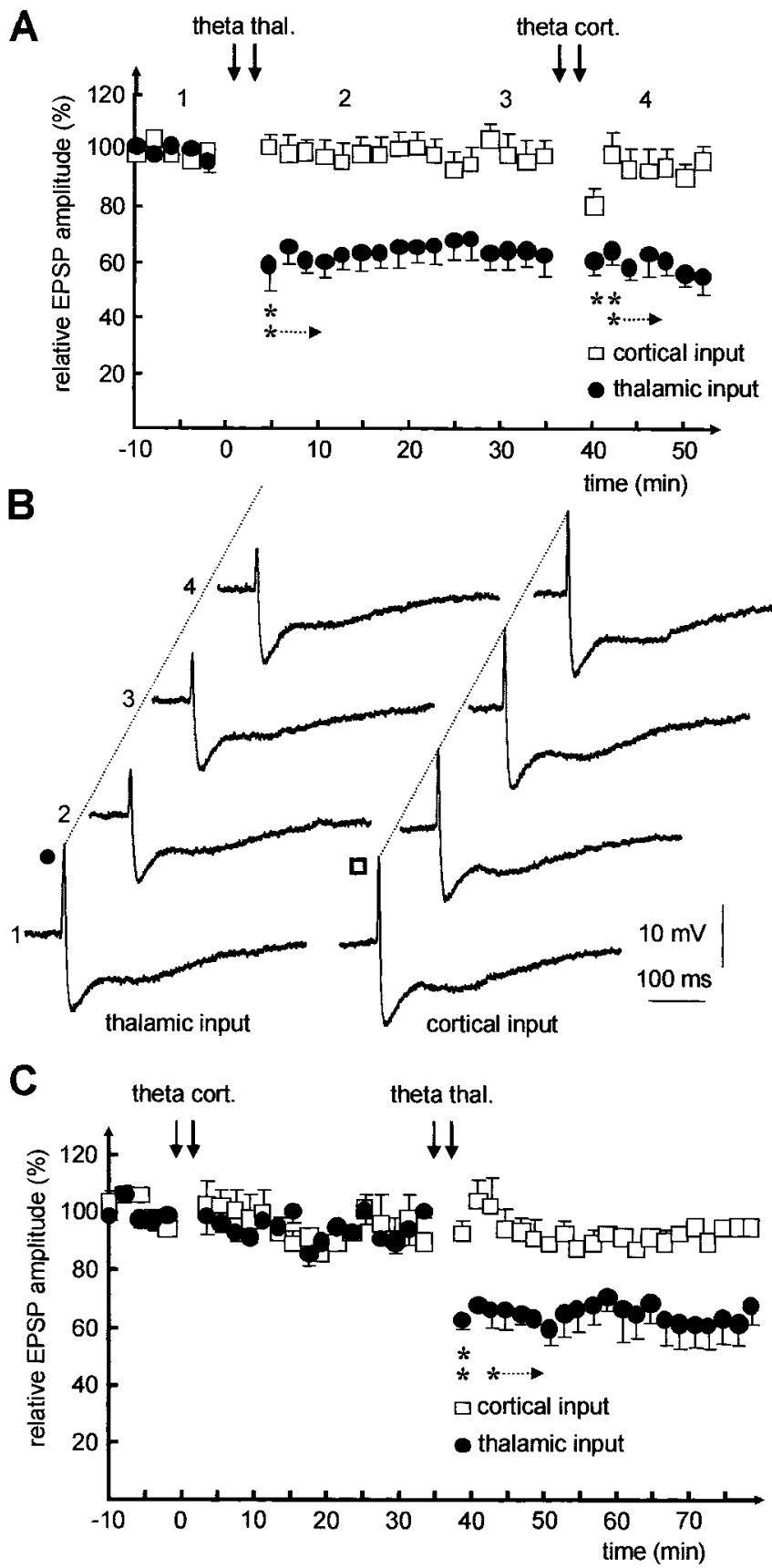

Figure 1. Homosynaptic lasting depression in the lateral amygdala. $A$, Normalized EPSP amplitudes evoked by single electrical stimuli (100 $\mu$ sec, delivered at $0.05 \mathrm{~Hz}$ ) of putative thalamic and putative cortical input fibers, before and after theta frequency stimulation $(8 \mathrm{~Hz}$ for $150 \mathrm{sec})$ of either input pathway, as indicated. Data were averaged from six projection neurons in six different slices. The period of theta frequency stimulation of thalamic and cortical input pathways is as indicated (theta thal., theta cort., respectively). Note the homosynaptic depression of EPSPs, and unchanged IPSPs (see $B$ ) after theta frequency stimulation of putative thalamic but not cortical input fibers $\left({ }^{*} p<0.05 ; * * p<0.01\right)$. $B$, Original recordings from one of the neurons in $A$ shown at different time points as indicated. Stimulus artifacts have been removed for clarity. Membrane potential at $-67 \mathrm{mV}$. $C$, Reversed order of theta frequency stimulation of the two pathways $(n=5)$. 


\section{Involvement of mGluRs}

Metabotropic glutamate receptors (mGluRs) are known to be involved in synaptic transmission in the amygdala (Rainnie et al., 1994; Holmes et al., 1996), in synaptic plasticity in the amygdala (Li et al., 1998; Wang and Gean, 1999), and in LTD in other brain regions (Ito, 1989; Linden and Connor, 1995; Bear and Abraham, 1996; Manahan-Vaughan, 1997). To explore the mechanisms of LTD in the LA, we tested the effects of mGluR group II antagonists and agonists. The group II mGluR agonist L-CCG (1-10 $\mu \mathrm{M}$ ) induced an input-specific slow-onset LTD of the thalamic pathway when applied to amygdala slices during continued control stimulation $(0.05 \mathrm{~Hz})$ (Fig. $2 A$; total $n=26)$. Subsequent theta frequency stimulation did not further increase the depression, suggesting saturable properties of this LTD. Higher doses of L-CCG $(10 \mu \mathrm{M})$ also reduced cortically induced EPSPs with a rapid time course that was often associated with membrane potential hyperpolarization as described previously (Rainnie et al., 1994; Holmes et al., 1996).

When the group II mGluR antagonist MCCG $(10-100 \mu \mathrm{M})$ was applied to the slice before theta frequency stimulation, no lasting synaptic depression was observed (Fig. 2C); instead, short potentiating effects on thalamically induced EPSPs were evoked. By itself, MCCG did not affect the amplitude of synaptic potentials evoked by single stimulation of either input pathway, membrane potential, or input resistance. Likewise, another mGluR group II antagonist EGLU $(10-100 \mu \mathrm{M})$ prevented the induction of LTD in the LA. These effects were seen in all tested neurons $(n=23$, MCCG; $n=9$, EGLU). Prevention of LTD was also observed after application of a phosphatase inhibitor in all tested cells (Calyculin A, $10 \mu \mathrm{M} ; n=7$; data not shown).

\section{Calcium dependence}

Calcium is known to be involved in the induction of LTD in a number of preparations (Ito, 1989; Linden and Connor, 1995; Bear and Abraham, 1996), including the basolateral amygdala (Wang and Gean, 1999). When neurons in the LA were loaded with BAPTA (200 $\mathrm{mm}$ in the recording electrode; $n=21$ ), the induction of LTD was inhibited (Fig. 3), which supports the likelihood of postsynaptic induction of LTD in this preparation. With BAPTA, no input specific changes occurred in these neurons with either thalamic or cortical theta-frequency stimulation. The slow decline of the relative EPSP amplitude of either input pathway was a reflection of the gradual decrease of the apparent membrane input resistance (Fig. $3 A$ ). During the presence of BAPTA, superfusion of the slice with L-CCG also failed to induce LTD ( $n=10$; data not shown).

\section{DISCUSSION}

\section{Mechanism of LTD}

The present study demonstrates input-specific, activitydependent enduring synaptic depression in the amygdala. The LTD of EPSPs comprises an example of homosynaptic depression similar to that described in other areas of the brain (Ito, 1989; Linden and Connor, 1995; Bear and Abraham, 1996). A polysynaptic effect, resulting from long-term potentiation of AMPA currents in GABAergic interneurons and associated increase in inhibitory influence on projection neurons (Mahanty and Sah, 1998), can be primarily ruled out, because $\mathrm{GABA}_{\mathrm{A}}$ - and $\mathrm{GABA}_{\mathrm{B}^{-}}$ mediated potentials increased only briefly $(<5 \mathrm{~min})$ in neurons that expressed stable LTD.

Although the exact pharmacology of LTD varies between preparations, mGluRs have been shown to be both necessary and
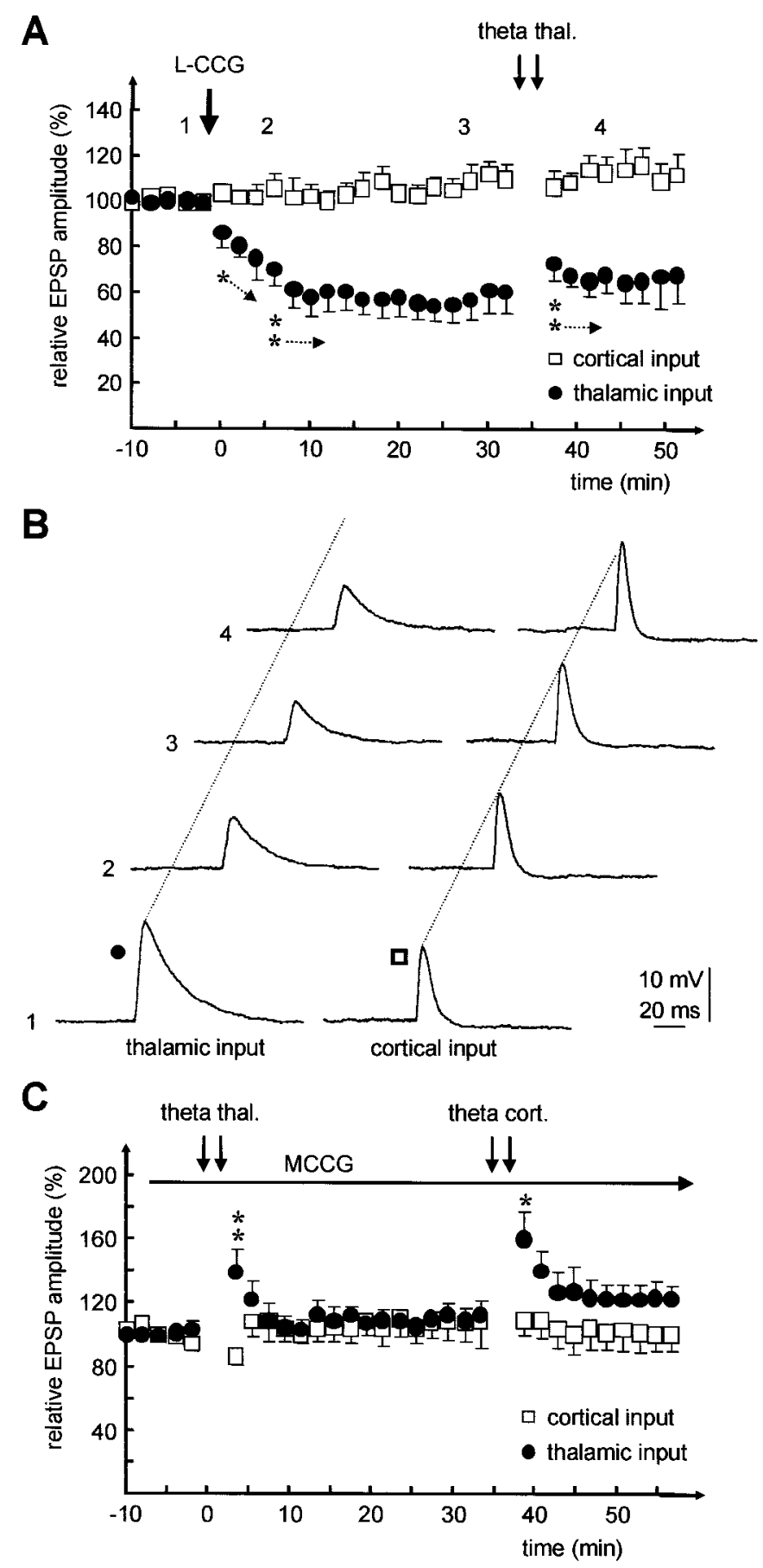

Figure 2. Involvement of group II mGluRs in homosynaptic LTD. $A$, Application of L-CCG $(10 \mu \mathrm{M})$ induces slow onset depression of EPSPs evoked by single stimuli of putative thalamic but not cortical input fibers $\left(n=4 ;{ }^{*} p<0.05 ;{ }^{*} p<0.01\right)$. $B$, Original recordings from one of the neurons in $A$ at different time points as indicated. Membrane potential at $-74 \mathrm{mV}$. C, The induction of synaptic depression is prevented by previous application of MCCG $(0.1 \mathrm{mM} ; n=5)$. Note short-term potentiation of responses evoked by stimulation of putative thalamic inputs. theta thal., theta cort., Period of theta frequency stimulation of thalamic and cortical input pathways, respectively.

sufficient for homosynaptic LTD induction (Linden and Connor, 1995). In the amygdala, group II mGluRs appear to be critically involved, as is indicated by the preventing effects of antagonists (Li et al., 1998; Wang and Gean, 1999; present study) and the 

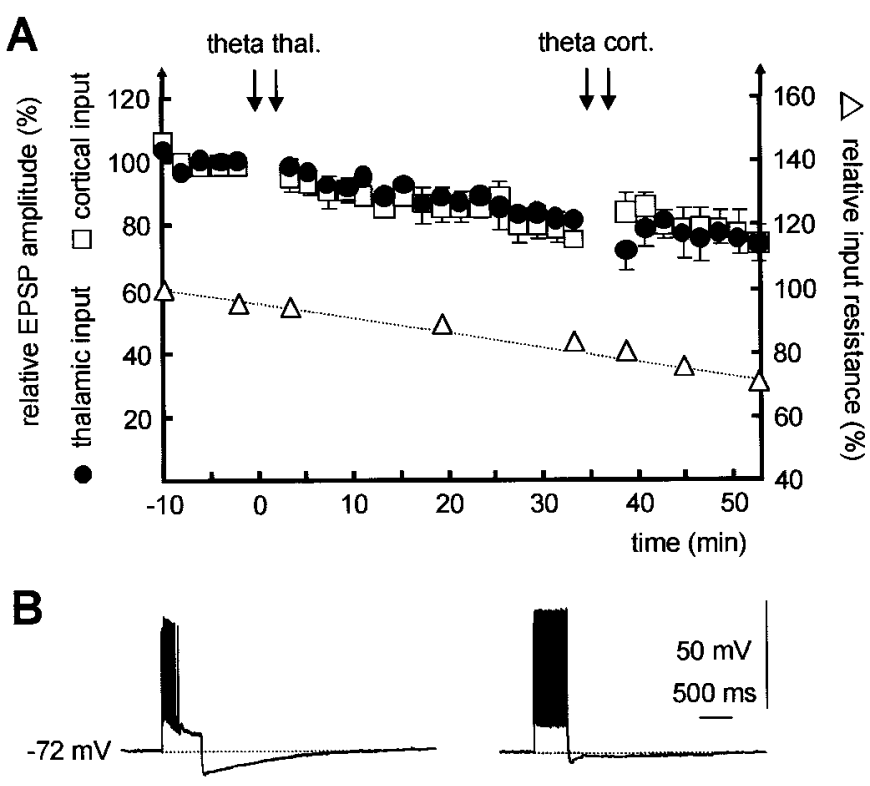

Figure 3. Significance of postsynaptic, calcium-dependent mechanisms for LTD. $A$, Loading of the recorded projection neurons with BAPTA (200 $\mathrm{mm}$ in the recording electrode) prevents input-specific changes upon theta frequency stimulation of putative thalamic (theta thal.) or cortical (theta cort.) input pathways $(n=7)$. Normalized values of membrane input resistance for the same neurons are shown at selected time points. Note the parallel decline of the relative EPSP amplitude and the membrane input resistance in BAPTA-loaded neurons. $B$, Loading of neurons with BAPTA was verified by the lack of spike frequency adaptation and reduced slow afterhyperpolarization in response to depolarizing current pulses: examples from one neuron illustrating the response to a depolarizing current pulse at 2 min after obtaining a stable impalement (left $t$ and at $70 \mathrm{~min}$ (right). The dotted line indicates membrane potential before current pulse.

finding that single stimuli are sufficient to induce LTD during the presence of a group II mGluR agonist (present study). The projection neurons in the LA, which receive convergent input from both cortical and thalamic pathways, express both AMPA and NMDA receptors, presumably with distinct populations of NMDA receptors occurring at putative cortical and thalamic inputs (Weisskopf and LeDoux, 1999). The question as to the type of glutamate receptors maintaining the reduction in synaptic strength could not be unequivocally assessed, because effects of antagonists on glutamate receptor subtypes were difficult to differentiate in the low-amplitude EPSPs. An NMDA receptor contribution is unlikely, however, because NMDA receptors associated with putative thalamic inputs to LA projection neurons possess a strong voltage dependence compared with those at cortical inputs (Weisskopf and LeDoux, 1999; but see Mahanty and Sah, 1999), and the feedforward IPSPs curtailing the EPSP can be assumed to essentially prevent activation of NMDA receptors. Therefore, it would appear that AMPA-type receptors are the predominant components maintaining the depressed EPSPs at thalamic inputs. This is supported by the observation that CNQX blocked the EPSP after LTD had been induced through theta frequency stimulation (our unpublished observations). Loading the recording electrode with BAPTA as well as local application of a phosphatase inhibitor on the slice prevented the induction of LTP, thereby corroborating recent findings by Wang and Gean (1999), which suggest that phosphorylation and dephosphorylation of AMPA receptors are involved in synaptic plasticity in the lateral amygdala. The exact basis for input- specific LTD is still unknown but may be related to the topographic arrangement of thalamic and cortical input fibers to the amygdala (LeDoux et al., 1990; Doron and LeDoux, 1999), spatial aspects of receptor distribution, and/or rapid redistribution of AMPA receptors (Carroll et al., 1999).

\section{Functional implications}

The finding that LTD was induced during theta frequency stimulation is particularly intriguing, in view of the propensity of projection neurons in the LA to produce rhythmic-oscillatory electrical activity at the theta frequency range and resonance behavior (Paré et al., 1995; Pape and Driesang, 1998; Pape et al., 1998). This electrophysiogical behavior has been proposed to facilitate the generation of phase-coupled oscillatory activity in synaptic circuits of the amygdala in response to sensory stimulation and to support the entrainment of amygdaloid neurons into network activity related to the theta rhythm in an extended temporolimbic network (Paré and Gaudreau, 1996; Collins and Paré, 1999). As a corollary of this, it is interesting to speculate that the homosynaptic LTD observed in the LA during theta frequency stimulation may be related to behavior associated with the generation of theta waves. Of particular interest here is the notion that the theta rhythm has been proposed to be a correlate of the inhibition of nonrelevant sensory systems during high arousal and to implement the basic processes for memory storage (Pavlides et al., 1988; Huerta and Lisman, 1993; Vinogradova, 1993; Sainsbury, 1998). The input-specific LTD observed may thus represent cellular sources that serve to regulate the balance between sensory thalamic and cortical input signals to the amygdala during those states. In particular, this regulation would function to reduce the influence of relatively undiscriminated stimulus information carried by thalamic fibers in favor of contextual stimulus analysis performed via cortical pathways during fear responses.

\section{REFERENCES}

Bear MF, Abraham WC (1996) Long-term depression in hippocampus. Annu Rev Neurosci 19:437-462.

Carroll RC, Lissin DV, von Zastrow M, Nicoll RA, Malenka RC (1999) Rapid redistribution of glutamate receptors contributes to long-term depression in hippocampal cultures. Nat Neurosci 2:454-460.

Collins DR, Paré D (1999) Reciprocal changes in the firing probability of lateral and central medial amygdala neurons. J Neurosci 19:836-844.

Danober L, Pape H-C (1998) Mechanisms and functional significance of a slow inhibitory potential in neurons of the lateral amygdala. Eur J Neurosci 10:853-867.

Dixon WJ, Massey FJ (1969) Introduction to statistical analysis, Ed 3. New York: McGraw Hill.

Doron NN, LeDoux JE (1999) Organizations of projections to the lateral amygdala from auditory and visual areas of the thalamus in the rat. J Comp Neurol 412:383-409.

Fanselow MS, LeDoux JE (1999) Why we think plasticity underlying Pavlovian fear conditioning occurs in the basolateral amygdala. Neuron 23:229-232.

Gean PW, Chang FC (1991) Bursting discharges in disinhibited amygdala slices: the role of excitatory amino acid receptors. Neuropharmacology 30:797-802.

Heinbockel T, Pape H-C (1999a) Input specific changes in synaptic efficacy in the lateral amygdala of the rat in vitro. Pflügers Arch [Suppl] 437:R123.

Heinbockel T, Pape H-C (1999b) Changes in synaptic efficacy after theta frequency stimulation in the lateral amygdala of the rat in vitro. Soc Neurosci Abstr 25:1738.

Heinbockel T, Pape H-C (1999c) Modulatory effects of adenosine on inhibitory postsynaptic potentials in the lateral amygdala of the rat. $\mathrm{Br} \mathrm{J}$ Pharmacol 128:190-196.

Holmes KH, Keele NB, Arvanov VL, Shinnick-Gallagher P (1996) Metabotropic glutamate receptor agonist-induced hyperpolarizations 
in rat basolateral amygdala neurons: receptor characterization, second messengers and ion channels. J Neurophysiol 76:3059-3069.

Huang Y-Y, Kandel ER (1998) Postsynaptic induction and PKAdependent expression of LTP in the lateral amygdala. Neuron 21:169-178.

Huerta PT, Lisman JE (1993) Heightened synaptic plasticity of hippocampal CA1 neurons during a cholinergically induced rhythmic state. Nature 364:723-725.

Ito M (1989) Long term depression. Annu Rev Neurosci 12:85-102.

LeDoux JE (1995) Emotion: clues from the brain. Annu Rev Psychol 46:209-235.

LeDoux JE, Farb CF, Ruggiero DA (1990) Topographic organization of neurons in the acoustic thalamus that project to the amygdala. J Neurosci 10:1043-1054.

Li H, Weiss SRB, Chuang D-M, Post RM, Rogawski MA (1998) Bidirectional synaptic plasticity in the rat basolateral amygdala: characterization of an activity-dependent switch sensitive to the presynaptic metabotropic glutamate receptor antagonist $2 \mathrm{~S}$ - $\alpha$-ethylglutamic acid. J Neurosci 18:1662-1670.

Li XF, Stutzmann GE, LeDoux JE (1996) Convergent but temporally separated inputs to lateral amygdala neurons from the auditory thalamus and auditory cortex use different postsynaptic receptors: in vivo intracellular and extracellular recordings in fear conditioning pathways. Learn Mem 3:229-242.

Linden DJ, Connor JA (1995) Long-term synaptic depression. Annu Rev Neurosci 18:319-357.

Mahanty NK, Sah P (1998) Calcium-permeable AMPA receptors mediate long-term potentiation in interneurons in the amygdala. Nature 394:683-687.

Mahanty NK, Sah P (1999) Excitatory synaptic inputs to pyramidal neurons of the lateral amygdala. Eur J Neurosci 11:1217-1222.

Manahan-Vaughan D (1997) Group 1 and 2 metabotropic glutamate receptors play differential roles in hippocampal long-term potentiation in freely moving rats. J Neurosci 17:3303-3311.

Maren S (1999) Long-term potentiation in the amygdala: a mechanism for emotional learning and memory. Trends Neurosci 22:561-567.

Maren S, Fanselow MS (1995) Synaptic plasticity in the basolateral amygdala induced by hippocampal formation stimulation in vivo. J Neurosci 15:7548-7564.

Maren S, Fanselow MS (1996) The amygdala and fear conditioning: has the nut been cracked? Neuron 16:237-240.

McKernan MG, Shinnick-Gallagher P (1997) Fear conditioning induces a lasting potentiation of synaptic currents in vitro. Nature 390:607-611.

Pape H-C, Driesang RB (1998) Ionic mechanisms of intrinsic oscillations in neurons of the basolateral amygdaloid complex. J Neurophysiol 79:217-226.

Pape H-C, Paré D, Driesang RB (1998) Two types of intrinsic oscillations in neurons of the lateral and basolateral nuclei of the amygdala. J Neurophysiol 79:205-216.

Paré D, Gaudreau H (1996) Projection cells and interneurons of the lateral and basolateral amygdala: distinct firing patterns and differential relation to theta and delta rhythms in conscious cats. J Neurosci 16:3334-3350.

Paré D, Pape H-C, Dong J (1995) Bursting and oscillating neurons of the cat basolateral amygdaloid complex in vivo: electrophysiological properties and morphological features. J Neurophysiol 74:1179-1191.

Pavlides C, Greenstein Y, Grudman M, Winson J (1988) Long-term potentiation in the dentate gyrus is induced preferentially on the positive phase of theta-rhythm. Brain Res 439:383-387.

Pitkänen A, Savander V, LeDoux JE (1998) Organization of intraamygdaloid circuitries in the rat: an emerging framework for understanding functions of the amygdala. Trends Neurosci 20:517-523.

Rainnie DG, Asprodini EK, Shinnick-Gallagher P (1991a) Excitatory transmission in the basolateral amygdala. J Neurophysiol 66:986-998.

Rainnie DG, Asprodini EK, Shinnick-Gallagher P (1991b) Inhibitory transmission in the basolateral amygdala. J Neurophysiol 66:999-1009.

Rainnie DG, Holmes KH, Shinnick-Gallagher P (1994) Activation of postsynaptic metabotropic glutamate receptors by trans-ACPD hyperpolarizes neurons of the basolateral amygdala. J Neurosci 14:7208-7220.

Rogan MT, Stäubli UV, LeDoux JE (1997) Fear conditioning induces associative long-term potentiation in the amygdala. Nature 390:604-607.

Sainsbury RS (1998) Hippocampal theta: a sensory-inhibition theory of function. Neurosci Behav Rev 22:237-241.

Vinogradova OS (1993) Expression, control, and probable functional significance of the neuronal theta-rhythm. Prog Neurobiol 45:523-583.

Wang SJ, Gean PW (1999) Long-term depression of excitatory synaptic transmission in the rat amygdala. J Neurosci 19:10656-10663.

Washburn MS, Moises HC (1992a) Inhibitory responses of rat basolateral amygdaloid neurons recorded in vitro. Neuroscience 50:811-830.

Washburn MS, Moises HC (1992b) Electrophysiological and morphological properties of rat basolateral amygdaloid neurons in vitro. J Neurosci 12:4066-4079.

Weisskopf MG, LeDoux JE (1999) Distinct populations of NMDA receptors at subcortical and cortical inputs to principal cells of the lateral amygdala. J Neurophysiol 81:930-934. 